the arms. From February 7 th to 16 th the temperature was irregular, never attaining the normal point or rising above ro ${ }^{\circ}$ F. The patient was cestless and semi-delirious at night. There was serere pain in the back
over the sacrum for which morphine hypodermic injections were given over the sacrum, for which morphine hypodermic injections were given periodically. The vaginal discharge was scanty and only slightly maloThe history of the case from this time was that of localised pelvic cellulitis going on to recovery.

CASE V - - C. C., a robust woman, 29 years of age, came under treatment on March gth. She had been vaccinated in infancy and three well-marked

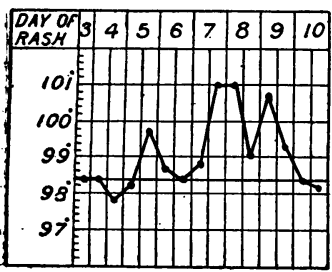
foveated scars were present. The rash (third day) was vesicular and of the semiconfluent type. The treatment already described was ordered. By the rath the pocks were only semi-pustular on the face. On the r4th the rash was at its height. about half, the pocks were distinctly pustular. The skin of the face was considerably swollen and there was slight conjunctivitis. Irritation was absent and no fotid odour could be detected. Desiccation was rapid during the next few days and the patient was up on the 20 th. There was a rise in temperature on the 13 th, $x_{4}$ th, and 15 th, with $101^{\circ} \mathrm{F}$. as the maximum. Beyond this there was no secondary fever. The most notable effect of salol in this case was the absence of irritation, even when there was distinct cedema of the face, and the mildness of the secondary febrile symptoms. Its influence on maturation was less obvious, although the latter appeared to be delayed The patient was permanently but very slightly marpear

was permanently but very slightly marked. Vaccinated in infancy, he had three fairly distinct scars. The rash was vesicular and semi-confluent. It had appeared three days previously. It had apirst three days after admission the vesicles enlarged somewhat, and over became pustular. Twenty-four hours later a smaller proportion of those on the body and limbs had matured. pustules were small and no irritation was felt. There was an absence of unpleasant odour. The rash now remained almost stationary for twenty-four hours, and then quickly dried up. On admission the tem perature was 102. $8^{\circ} \mathrm{F}$., whence, after a slight rise, it fell to the normal point within three days. Excepting a rise to $99.8^{\circ}$ on $\mathrm{March}$ a4th, it then remained normal. If this was the effect of the salol, an inference difficult to reject, the benefit obtained was is especially dangerous.

Casp vil She was hod been vaccinated in infancy, three faint scars being left. There was nothing noteworthy in the patient's past history. The rash was in the fourth day, coherent on the face, and fairly profuse on the limbs and body. It was vesicular.

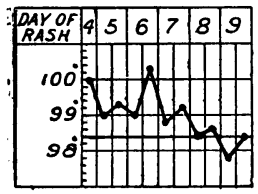
but on the face the vesicles were in the earliest stage of pustulation. Salol was given in rograin doses four-hourly. The rash matured very slowly, and on its seventh day only about hal the vesicles had become distinctly pustu'ar. On the forehead and left angle of the mouth were confluent patches where the suppurative pro cess was severe. The temperature for the first five days after admission was slightly raised and then remained normal. At one time there was trivial irritation, but never any offensive odour. The most noticeable feature in this case was the delayed maturation. Apart from the confluent patches permanent scarring appeared improbable.

CASE VIIr.-Mrs. P., aged 38, a multipara, seven months pregnant, was admitted on March rath. As a result of vaccination in infancy, three faint scars were just visible in a strong light. The rash was semi-confluent on the face and extremities. It had

appeared thirty-six hours preSalol was given in doses totalling to 60 grs. daily. It is unnecessary to detail the subsequent history of the rash sub its of the rash, as its development was typlcal, with almost unmodified pustulation. The secondary fever was mild. There was some offensive odour for forty-eight hours, but the patient did not complain of any irritation palms and soles. The in the palms and soles. The salol of spirits, and towards the end of of spirits, and towards the end of

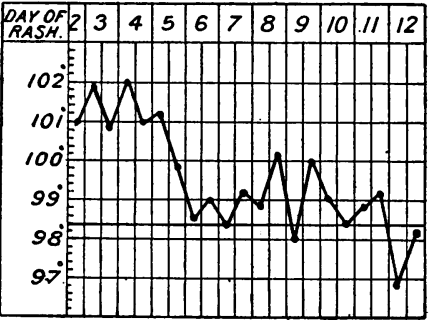

and scanty. The fact that the patient did not abort is interesting. It will be noted that in this case the conditions were specially favourable for treatment by salol. The rash was in its earliest stage, and the patient was able to take the drug until convalescence was complete. Yet no definite effect on maturation was manifest. It can, however, be said that the case ran an exceptionally favourable course, with mild secondary fever, no irritation, and a practical absence of scarring.

Conchusions.

It appears from the above series of cases that salol may practically avert general pustulation (for example, Case r), and even have a partial abortive effect when given after maturation has commenced (Case II). The influence of the treatment on maturation is, however, not constant in degree, and in one case was almost nil. Short of an abortive effect, it almost invariably hinders pustulation, so that the pustules form tardily, the process being imperfect in a much higher proportion than usual. The cutaneous inflammation is slight, and irritation commonly absent even in confluent cases. There is generally an entire absence of unpleasant odour. Scarring is inconsiderable and often absent, the scabs scaling off with great rapidity. The most remarkable effect of the treatment is its effect on the secondary fever, which, if not absent altogether, is as a rule of little importance.

These results appear to us to resemble, but exceed, those obtained by the red light treatment.

On the whole, the statement is justified that salol affords a means of treating small-pox superior to the methods in vogue.

\section{THE RADICAL CURE OF FEMORAL HERNIA.}

Br T. E. GORDON, M.B.UnIV.Dub., F.R.C.S.I., Surgeon to the Adelaide Hospital, Dublin.

Mr. W. H. BenNeTt, writing in 1893 of the radical cure of femoral hernia, says:

The effectual treatment of the ring and canal is a problem which has yet to be solved......The truth is that no plan for dealing with the aperture through which a femoral hernia comes will be found to be permanently good which does not include the essential detail of placing a barrier across
the upper aspect of the femoral ring..... Unfortunately the detail alluded to can only be carried out by performing an abdominal section, by means of which in the cadaver it is quite easy to dissect up and stitch a mass of muscle, etc., across the ring. In the living this operation would, I think, Woo severe and difficult to justify its performance.

With Mr. Bennett's dissatisfaction with methods at present in vogue directed towards the radical cure of femoral hernia I imagine many surgeons will be disposed to sympathise. The operation which is, I suppose, most commonly practised, aims at occluding the opening by a suture or sutures passed through the fibrous ring in front of and behind the crural canal. This method I believe to be wrong in principle and disappointing in practice. These ligamentous structures do not readily lend themselves to the process of union, and probably as a general rule separate as soon as the ligature material ceases to keep them in apposition.

Mr. Lockwood expresses himself satisfied with an operation which he is accustomed to perform; he brings together the ligaments of Hey and Cooper. But this is open to the objection just alluded to, and is, moreover, a striking example of closure of the lower-the wrong-end of the canal.

For a long time I have thought that a more rational procedure would be to expose the region above Poupart's ligament by a division of the aponeurosis of the external oblique. By this means only did it appear to me possible to satisfactorily occlude the upper end of the crural canal. I find that Tuffier in 1896 recommended this procedure, but the subsequent and essential step, the closing of the opening, he effected by a method which could have been accomplished nearly, if not quite, as well by operation from below.

I have from time to time tried different devices on the dead subject, and that which appeared to me to give most promise of success I carried out on April 24th at the Adelaide Hospital on a woman about 45 years of age. I was assisted by my colleague, Mr. F. T. Heuston.

The structure which is most at fault in cases of femoral hernia is probably Gimbernat's ligament, and I would describe the present method as a reinforcement of that structure.

The incision was commenced at a point about 2 inches from the pubic spine and $\frac{3}{4}$ inch above Poupart's ligament; thence it was carried inwards as far as the region of the hernia, and here it was curved to descend vertically over the sac. The aponeurosis of the external oblique was exposed in the first part of the incision, the sac of the hernia in the second. The sac was fully isolated from its surroundings. Next an opening was made above Poupart's ligament, in the direction of the fibres of the aponeurosis. The sac was now easily dislodged, and with the adjoining peritoneum pushed up from the region of the upper end of the crural canal. The fibres of the trans 
versalis and internal oblique muscles and the conjoined tendon were now clearly defined, and the muscle fibres were drawn down by catgut sutures and placed against the pectineus muscle, from the surface of which the fascia had been in part removed. The muscle was also fixed to Poupart's ligament by sutures passed at a higher level than the first series. This was done so as to pack down as much muscle fibre as possible against the opening, and also to relieve any tension that might be thrown on the primary sutures. The sac was treated somewhat after the method of Kocher. Over all a continuous suture closed the slit in the fibres of the aponeurosis. The closure of the crural canal by this means seemed to me very satisfactory and it was effected with great ease.

There are two objections which may be urged against the operation. First, there is a danger of wounding the deep epigastric artery-and this, as a matter of fact, happened in the present instance. I do not regard this as an accident of any serious consequence. Secondly, a direct inguinal hernia may result. I do not myself think there need be much anxiety on this score, for very few fibres of the aponeurosis are divided, seeing that the opening is made in the direction in which they naturally run, and also because the conjoined tendon is well drawn down to protect this region.

I am not certain about the best method of dealing with the sac. It might be better to remove it altogether and stitch up the rent in the peritoneum.

\section{A CASE OF ENTERIC FEVER OF THREE MONTHS' DURATION.}

By WILLIAM MURRELL, M.D., F.R.C.P., Physician to Westrinster.Hospital.

THE following case presents many points of interest :

C. S., a clerk, aged 28, was brought to the Westminster Hospital on an ambulance on November 18 th, 1899 , suffering from enteric fever. He had been ill since November rst, and had been nursed at home. On admission his temperature was $10^{\circ}$, and he was in an extremely prostrate condition. No enteric spots were to be seen, and none appeared during the whole course of his stay in the hospital. No enlargement of the spleen could be in size.

At 8 P.M. on the night of admission the temperature was $1036^{\circ}$, and he had passed a typical typhoid stool. The urine had a specific gravity of ro24, was acid in reaction, and free from sugar and albumen. Widal's reaction was obtained without difficulty.

3 pints of milk, 5 ounces every alterpate hour. On the 21st the temperature fell suddenly to $998^{\circ}$, and a few hours ing week the temrerase hæmorrhage from the bowel. During the following week the temperature ranged from $1 \mathrm{~T}^{\circ}$ to $104^{\circ}$, and the patient reThe bowels were open either once or twice a day, the motions being of the same character. He was now on 9 ounces of brandy in the twentyfour hours. On November 25 th he was found to have some bronchitis, but there was no pneumonia. There was some expectoration, which was examined for tubercle bacilli, but none were found. On December 3 rdthat is, on the thirty-third day of the illness-he had a sharp attack of diarrhœe and for the remainder of the week had from two to seven motions a day. The temperature rose to $1048^{\circ}$, and he had to be sponged two or three times a day. His pulse was usually $3_{3 \circ}^{\circ}$ and of poor quality, and his general condition was unsal isfactory. On December 6 th, 7 th, and 8th he was given an enema of 2 ounces of mucilage of starch with half a drachm of tincture of opium. This was retained, but exerted no influence on the frequency of the motions. On December oth he was crdered drachm doses of bismuth carbonate in milk and this checked the diarrhœea. During the following week the temperature ranged from $102^{\circ}$ to $103^{\circ}$, and the bowels were open from four to six times a day. In the next week the tem dently steadily losing ground. The only hopeful feature was that the three pints of milk and 9 ounces of brandy were taken with unfailing regularity.

Un Christmas Day, the fifty-fifth day of his illness, he was watched with unusual care to make sure that nothing was given him by visitors to the wards. On the following day, however, his temperature rose to $103.2^{\circ}$. At noon on December 27 th it was ro3..$^{\circ}$. At 4 P.M. he was given 5 grs. of phenacetin. An hour later the temperature had fallen to sor: $4^{\circ}$. At 8 P.M. he had a severe rigor lasting over half an hour, for which stimulants had to be given freely; the temperature fell to $100^{\circ}$, rising again to $102^{\circ}$ at midnight. On December 28 th at 4 P.M. the temperature was $103.2^{\circ}$ and he was given another dose of phenacetin, $5 \mathrm{grs}$. This was followed by a prolonged and very severe rigor, and at 8 P.M. his temperature was $96^{\circ}$, a rall of $7.2^{\circ}$ in four hours. At midnight, however, the temperature was 104.2 ${ }^{\circ}$, showing a recovery of 8.2 $1 \mathrm{n}$ four hours. On January Ist, the sixty-second day of the twent agaln drach dos o bismutcarbonatewerosuccoul chat pat pagne rreely in addition to the brandv. Strychnine and digitalis were also ro $3^{\circ}$, his pulse was almost imperceptible, and the motions were passed constantly under him. For many days he had been unconscious, only muttering to himself at intervals. He was given an enema of 2 drachms of Warburg's tincture in an ounce of milk, but it was not retained. On the following day 2 drachms were given by mouth, and there was some improvement. On January rith Warburg's tincture was ordered in doses
of 3 drachms twice a day, and almost immediately the diarrhoea was controlled, the temperature fell to $\mathrm{xc}^{\circ}$, and the pulse improved in quality.

On January risth a more liberal dietary was adopted, and the patient was ordered, in addition to his milk, a teaspuonful of plasmon every alternate hour. This was taken without difficulty, there was no rise in temperature, and the bowels were moved only once in the twenty-four
hours. This was practically the turning point in the patient's illness. The plasmon was continued for a week, and at the expiration of that The plasmon was continued for a week, and at the expiration of that
time the patient was given solid food. It was not howerer, until January 2oth, the eighty-first day, that the temperature fell to normal. From this day his appetite became ravenous, and on January 23 rd his dietary consisted of chicken and potatoes, beef tea (12 ounces). bread, four eggs, port (4 ozs.). He was allowed up for the first time on February 8th, the port (4 0z8.). He was allowed up

The long period during which the temperature was maintained is remarkable. It was not a question of relapse, for there was never any complete defervescence, and it was not post-typhoid pyrexia, for the diarrhoa with typical stools continued almost up to the end. The freedom from complications is a subject for congratulation, for, with the exception of a transitory attack of bronchitis there were none. There was never any dulness either at the apices or at the bases of the lungs, and the expectoration showed no trace of tubercle bacilli.

It is noteworthy, considering the large amount of fluid taken for so considerable a time, that there was no distension of the abdomen. There was never any doubt about the diagnosis, and Widal's reaction was obtained from the first. The case was practically one of the ambulatory type, for although the patient did not walk to the hospital, he was moved a considerable distance in the third or fourth week of the disease. We have taken November ist as the date of the onset of the illness, but that was the day on which he took to his bed, and he had been ailing for many days previously. During the first eighteen days he was treated at home, and it is probable that the nursing was not of the best. He had been drinking heavily for a considerable period before the onset of the illness, and this is not a good preparation for passing through so grave a crisis.

This case illustrates several therapeutical points. The enems of opium is useful in checking many forms of diarrbœa, especially the diarrhcea of advanced phthisis, but it is useless in the diarrhœ3 of enteric fever; at all events in this case it proved of no avail. The carbonate of bismuth in drachm doses administered in milk gave excellent results, probably by its mechanical action, in covering over and protecting the ulcerated Peyer's patches. The maximum dose of bismuth carbonate given in the B.P. is 20 graing, but this is far too small, and there is not the slightest danger in giving drachm or even half-ounce doses. At one time this galt contained traces of arsenic and tellurium-indicated by the "bismuth breath"-as impurities, but this is a thing of the past, and the drug is now supplied in a condition of perfect purity, so that it can be administered freely, without fear of producing toxic symptoms.

Many authorities speak highly of the value of antipyretic drugs in the treatment of enteric fever, and when the temperature persistently remains above $103^{\circ}$ recommend the administration of malakin, lactophenin, or phenacetin. Phenacetin, especially in from 10 to 15 .grain doses, is said to be free from danger, but this is not my experience, and in this case on two occasions a single 5-grain dose produced a condition bordering on collapse, and undoubtedly endangered the patient's life.

The administration of Warburg's tincture at the most critical period of this man's illness was attended with the best possible results. It may be objected that it is inexpedient to use proprietary medicines, but the composition of this preparation is no longer a secret. As long ago as 1875 Professor W. C. Maclean of Netley, with Dr. Carl Warburg's permission, published its formula and mode of preparation. It is a proof spirit tincture containing sulphate of quinine ( 1 in 50 ), aloes ( $I$ in 40 ), opium ( $I$ in 4,000), with rhubarb, camphor, myrrh, gentian cubebs, zedoaria boletus, and various other substances, chiefly aromatics. My first experience of it was in a case of pneumonia'I saw many years ago with the late Sir Richard Quain. The patient was apparently moribund, but 